\title{
General trends in the soft bottom environment of the Ekofisk region, Norwegian sector
}

\author{
S. M. Bakke \& S. A. Nøland \\ Det Norske Veritas (DNV), Norway
}

\begin{abstract}
The environment in the North Sea has been investigated over several years and since 1996 the environmental monitoring of the oil activity in the Norwegian sector of the North Sea and the North Atlantic has been performed in regions, covering large areas. This paper gives an overview of the general trends over years in Region I, the Ekofisk area. The benthic macro fauna community in this region is disturbed to varying extents, which seems to be a consequence of the activities in the area, physical disturbances and a diffuse organic load from various sources affecting the North Sea. The trend analyses of fauna communities in Region I indicate reduced supplies of available organic material and a positive development in the fauna community that reveals an ongoing improvement in the environment until at least $500 \mathrm{~m}$ from the oil field centres. Keywords: environmental monitoring offshore, North Sea, sil, ecological quality, soft bottom fauna, sediment, hydrocarbons, organic enrichment.
\end{abstract}

\section{Introduction}

Increasing human impacts from both land based and offshore activities have resulted in high organic loads and an increase in the content of hydrocarbons in the sediment, which have a significant effect on the North Sea environment (according to amongst others McGlade [1]). Increasing numbers of opportunistic species and an increase of biomass have been caused by increasing food availability for the benthos in the whole North Sea according to Kröncke and Bergfeld [2].

From the 1980s there have been increasing focus on the environmental problems in the North Sea and a number of actions have been implemented with different efforts from the countries around the North Sea. An important organ 
have been the North Sea conferences, which started in Bremen in 1984, where political commitments have been made to take certain measures aimed at protecting or enhancing the environment of the North Sea. Important agreements of the North Sea Ministers are now taken forward through the OSPAR Strategies, most of which were adopted at Ministerial level in 1998 and are aimed at guiding OSPAR's work.

An OSPAR decision relevant for the results of this study is the PARCOM Decision 92/2 on the Use of Oil-Based Muds, which have been implemented in several European countries during the 1990s. In Norway the discharge of oil based mud and drill cuttings have been prohibited since 1 January 1993. Since then the oil companies have been used mainly synthetic and water based drilling fluids. Lately there has been an increasing trend with use of water based drilling fluids.

\subsection{Environmental monitoring - Norwegian sector}

Production of oil in the Norwegian sector of the North Sea began at the Ekofisk field in 1971. There has been some environmental monitoring of the sediments and its fauna in the North Sea during the years, starting in 1970s and carried out during the 1980s and 1990s. However, in 1996 a regional approach was introduced to obtain a more holistic picture of the development and trends in the major regions in the Norwegian sector. Since then the Ekofisk area (Region I), has been monitored every third year (1996, 1999, 2002 and 2005). Time series from surveys using standardised method's (guidelines, regulations) performed by accredited consultants are stored in MOD (Marine Offshore Database), which has made it possible to study trends in the chemical and biological results.

The Ekofisk region is limited to the Norwegian Continental shelf from $56^{\circ} 02^{\prime} \mathrm{N}$ to $57^{\circ} 52^{\prime} \mathrm{N}$ and from $02^{\circ} 46^{\prime} \mathrm{E}$ to $04^{\circ} 32^{\prime} \mathrm{E}$. Figure 1 shows the oil fields in the region.

\subsection{Macro fauna studies}

Sediment macro fauna studies, utilising biodiversity measurements/assessments, are an essential part of the environmental monitoring. It provides an overview of the trends and effects and an environmental status. Because the majority of marine habitats are within soft substrates (sediments), the macro fauna (benthos) inhabiting the sediments represent a major component within the marine environment.

Studies of benthos are useful in understanding changes in biological diversity, and the species are recognized as an essential baseline for understanding diversity. The use of benthos in evaluating marine pollution is especially effective in assessing long-term changes and detecting input from diffuse sources. The benthos reflects the effects of pollutants or organic enrichment by detectable changes in population. Other advantages include the fact that many benthic organisms are resident and naturally abundant and diverse. Benthic monitoring is also a relatively sensitive, effective and reliable technique that can 
detect subtle changes that serve as an early indicator before more drastic environmental changes occur.

This study focuses on the macro benthic community in Region I, the Ekofisk area. In the later years there have been major alterations in the macro benthic fauna communities. These alterations have made it difficult to interpret results from single years surveys based on traditional statistical analyses. The area is influenced by oil activities, and various land based sources as well as physical disturbance due to relatively shallow waters. To identify the causes of observed impacts has been one of the major challenges. For detailed results from the survey in 2005 at Ekofisk it is referred to DNV technical report [3].

\section{Materials and methods}

\subsection{Data material}

The data analysed in this study has been sampled in regional surveys carried out on behalf of the oil companies in the Ekofisk region in 1996, 1999, 2002 and 2005. The number of sampling locations has been $150-200$ per survey. From each location 5 samples $\left(0.5 \mathrm{~m}^{2}\right.$ surface area) have been analysed for macro benthic fauna in accordance with the guidelines from the Norwegian Pollution Control Authority. The process of biological analyses is outlined in Figure 2.

\subsection{Statistical analyses}

Fauna similarities between stations have been calculated by the use of BrayCurtis similarity index, Bray and Curtis [4]. The resulting similarity matrices were utilised in multivariate analyses (classification and ordination) in order to group stations and assess gradients in the benthic communities. These methods were: hierarchical agglomerative classification with group-average sorting, Lance and Williams [5], ordination with non-metric Multi-Dimensional Scaling (MDS), Kruskal and Wish, [6] and Principal Components Analysis (PCA). Classification MDS and PCA ordination were carried out using the programmepackage PRIMER (Plymouth Routines In Multivariate Ecological Research).

\section{Results and discussion of the general trends in the region}

The sediments in the region consist mainly of fine sand. The total organic matter contents measured in the sediments top layer in 2005 were generally low, despite a known high supply of organic matter from various sources into the North Sea. According to Phillips and Rainbow [7] direct chemical analyses of water and sediment, which are usually very sensitive and accurate, do not necessarily reflect the actual ecological state. Further, it is well documented that unconsolidated, fine-grained sediments and their contents of organic matter do not settle on the seabed in high-energy water environments. Due to frequent wave and/or current induced re-suspension this material is repeatedly brought back into the water column. Thus representing an additional source of organic 
matter, in the boundary layer between sediment and water, available to the benthic fauna.

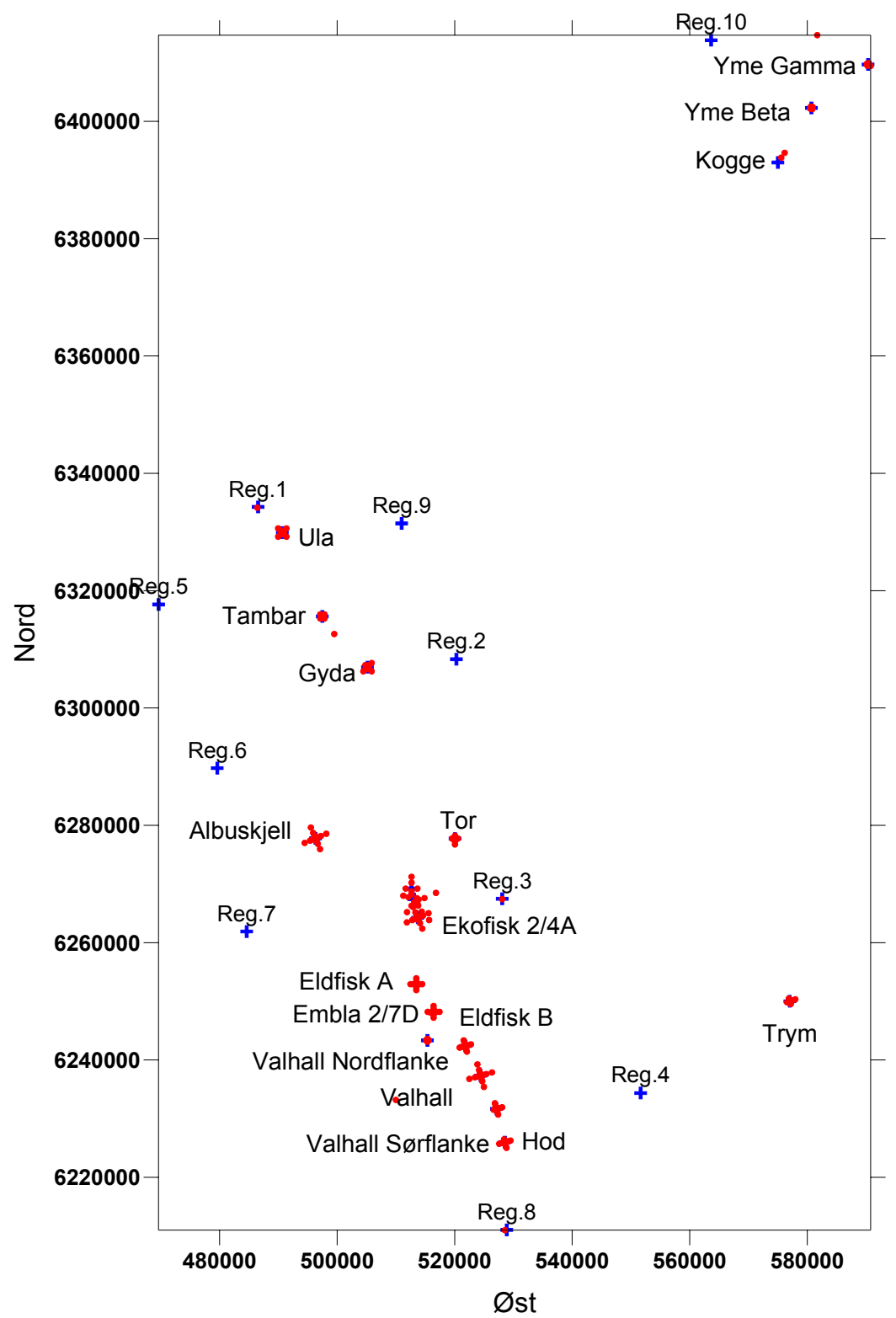

Figure 1: Region I - Ekofisk, overview of installations included in the 2005 survey. Reg = Regional stations (assumed not affected by oil activities). Data from the Yme area is not included in this study. 


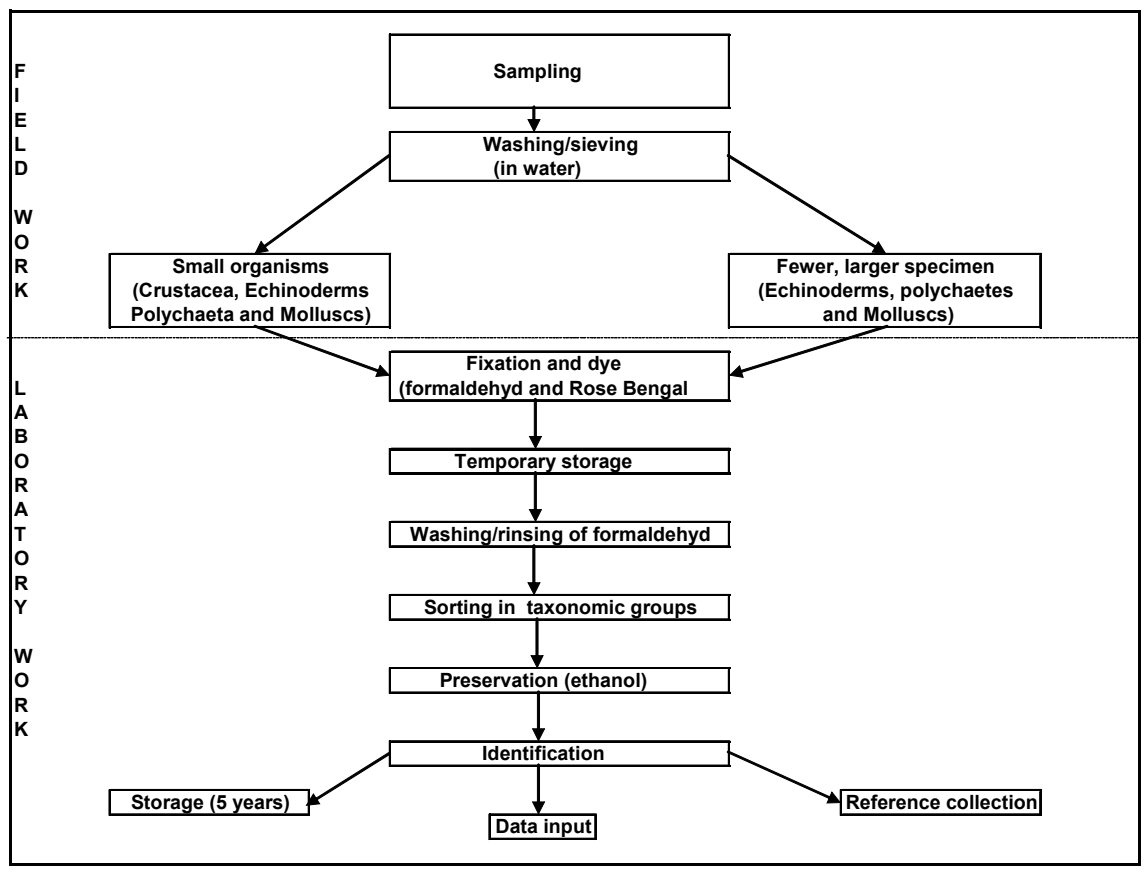

Figure 2: Outline of biological analyses in sediment monitoring, DNV Biology Laboratory.

In addition, stored organic matter (including degraded petroleum hydrocarbons) in the deeper layer of the sediments will be available for burrowing benthic species, which also trough bioturbation will carry this material to the top layer.

According to Eisma and Kalf [8] accumulation and deposition of suspended matter in the North Sea occur predominantly in a few areas only (the Waddensea, the German Bight and the Skagerrak/Norwegian Channel). However, there were, found relatively high levels of hydrocarbon in the vicinity of most of the fields in 2005. With a few exceptions, the concentrations were considerably lower compared to 2002. Generally, the results from the 2005 survey at Region I show that the levels of hydrocarbons, barium and metals have decreased compared to the 2002 survey.

\subsection{The significance of Myriochele oculata and other dominating species in the region}

\subsubsection{Summary of findings up to 1990}

A review of Hartley [9] after ten years monitoring at the Ekofisk field reveal that the benthic fauna was uniform across the Ekofisk oil field and there were not found any hydrocarbons in the sediments in 1973. In 1975 the benthic fauna showed reduced densities of several common species close to the central 
complex, in particular Myriochele sp. and also Amphiura filiformis (both species are known to be sensitive to hydrocarbons and moderate tolerant to organic enrichment according to among others Hiscock et al. [10], Pearson and Rosenberg [11] and Simboura and Zenetos [12]). Films of oil and oily clots were observed in a number of samples. In addition, there had been an increase in the content of hydrocarbons in the sediment. In 1977 and 1978 reductions were still observed in the densities of several common species, in particular Myriochele sp. In 1980, the decline of the Myriochele sp. continued across the centre of the field but the densities of the Cirratulid polychaetes (hydrocarbon tolerant according to Hiscock et al. [10]) increased. In 1981 it was concluded that the density of the formerly dominating Myriochele sp. had declined across the whole survey area, out to $8 \mathrm{~km}$ from the field centre. The densities of opportunistic Cirratulid polychaetes were similar to those recorded in 1980. In 1983 there were still reductions in the abundance of Myriochele, while the numbers of Cirratulid polychaetes had increased. Gray et. al [13] found that Chaetozone setosa (Cirratulidae) was increasing dramatically towards the more polluted sites around the Ekofisk- and Eldfisk fields, while M. oculata was found at the sites characterized as "unpolluted".

\subsubsection{Summary of findings $1996 \mathbf{- 2 0 0 5}$}

In 1996, high numbers of the Cirratulid C. setosa and to some degree ribbon worms (Nemertea) were still found.

These species are known to be very tolerant to hydrocarbon contamination and also strong indicators of organic enrichment and common in the negative end of the transition zone, according to amongst others Hiscock et. al [10] and Pearson and Rosenberg [11], were dominant in the central part of the Ekofisk region.

In 1999 there was observed a shift in the community. Particularly the numbers of $C$. setosa had been reduced, and the numbers of M. oculata had increased in the region. A further increase of this species was observed in 2002. However, there was not possible to see any clear pattern or trend in the distribution and abundance of this species related to the activity in the area neither in 1999 (DNV, [14]) nor in 2002 (DNV, [15]). The species flourished around the fields in various directions and distances, including reference- and regional stations ("unpolluted" stations). However, the increases in abundance of this species were not evident at the stations located close to the field centres $(100 \mathrm{~m})$, which had relatively high hydrocarbon levels in the sediments.

In 2005 there was registered a general significant decline in the abundance of M. oculata and a higher number of total species together with higher biodiversity indices in the region compared to the last survey. The distribution and the abundance of this species in the area had changed and it was possible to trace patterns and trends in the distribution of $M$. oculata. In 2005 the highest abundances of this species were found at the $250 \mathrm{~m}$ and $500 \mathrm{~m}$ stations around the oil fields, while it was decreasing in numbers with increasing radius from the field centres. This species was still dominant in the central part of the region, 
however it did not flourish independent of distance and directions from the field centres, and the analyses indicate an ongoing positive trend.

In the following the trends in the fauna community at the $250 \mathrm{~m}$ and $500 \mathrm{~m}$ stations in the central Ekofisk region are elaborated.

\subsubsection{Trend analyses of the $250 \mathrm{~m}$ and $500 \mathrm{~m}$ stations in the central region}

\section{0 m stations}

A similarity analysis for fields in the central part of the region (Ula, Gyda, Tambar, Tor, Hod, Eldfisk A, Eldfisk B, Valhall, Ekofisk Center and Ekofisk A) have been performed. The stations divide mainly by years, see Figure 3: and the following pattern was revealed:

The average abundance of $M$. oculata at $500 \mathrm{~m}$ was relatively similar in 1996 and 1999. Furthermore, the average abundances of strong indicator species within the families Cirratulidae (mainly C. setosa) and Spionidae, both able to live as deposit feeders, have decreased from 1996 to 1999. At the same time the average abundances of suspension feeders such as Ditrupa arietina, also moderate tolerant according to Simboura and Zenetos [12], are seen to increase. Further decreases in the species within the families Cirratulidae and Spionidae are registered in the 2005 survey.

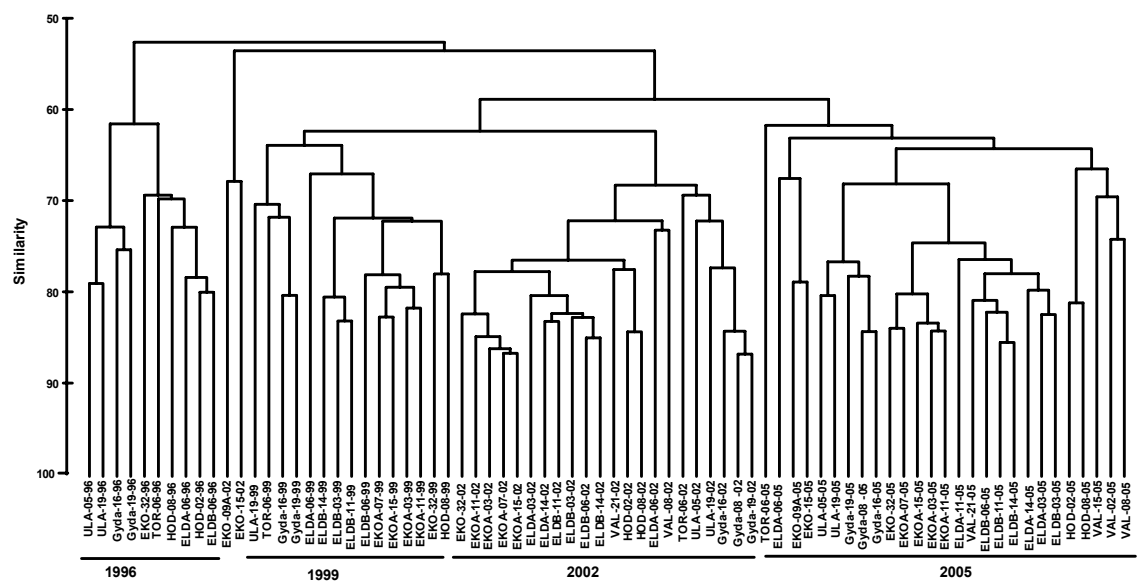

Figure 3: Dendrogram, 500 m stations. Region I - 2005.

From 1999 to 2002 a significant increase in the abundance of M. oculata was registered (common with $>1000$ individuals at each stations site in 2002) together with an increase in carnivore species as Paramphinome jeffreysii and other suspension feeders such as A. filiformis, Apistobranchus tullbergi, Tricobranchus roseus and Cerianthus loydii.

From 2002 to 2005, the abundance of M. oculata has decreased significantly allowing a continued increase of other suspension feeders and with that also a higher biodiversity. An increase in the numbers of suspension feeding species 
and a decrease in deposit feeding organisms indicate that available organic matter (including degraded petroleum hydrocarbons) decreases. Pearson and Rosenberg [11] documented that the number of species and abundance of the benthic infauna change substantially. With a high organic load the fauna is dominated by a few opportunistic or pollution-tolerant species which mostly are deposit feeders. Suspension feeders and surface detrital feeders typically decrease in abundance or are eliminated.

\section{0 m stations}

The fields that were included in this analysis were limited to Ula, Gyda, Tambar, Tor, and Ekofisk A. The stations mainly divided by year, similar to the $500 \mathrm{~m}$ stations (see Figure 3) and the following general pattern was revealed.

At the $250 \mathrm{~m}$ stations, the abundance of $M$. oculata has increased over the years to an average of 1700 in 2002 and 2005 from less than 100 individuals in 1996. The increases from 1996 to 1999 and 2002 were significant between years. Furthermore, the numbers of individuals in the families Spionidae and Cirratulidae (mainly C. setosa which is a hydrocarbon indicator) have decreased over the years from 1996 to 2002. The decrease did not continue to 2005 .

In contrast to the pattern at the $500 \mathrm{~m}$ stations between 2002 and 2005 there have been minor changes in the fauna composition at the $250 \mathrm{~m}$ stations.

Comparison of the $500 \mathrm{~m}$ and $250 \mathrm{~m}$ stations reveals an ongoing improvement in the fauna at the $500 \mathrm{~m}$ stations during recent years. At the $250 \mathrm{~m}$ stations the improvement in the fauna community reveals a less obvious trend and there have not been any general improvements from 2002 to 2005 at these stations. However, the ongoing process is possibly somewhat slower at the 250 $\mathrm{m}$ stations. The fauna at $250 \mathrm{~m}$ in 2005 could be characterised as about the same state as the $500 \mathrm{~m}$ fauna in 2002 .

\section{Main lines and conclusion}

The results from the survey in 2005 indicate improvements in the soft bottom fauna inhabiting the sediments in the Region I. In the early 1970's Myriochele sp. and Amphiura species were a natural and common part of a fauna community dominated by suspension feeders. The abundance of the bristle worm Myriochele $s p$. which is relatively sensitive to hydrocarbons decreased significantly in the fauna out to $8 \mathrm{~km}$ from the Ekofisk field centre during the late 1970s and the 1980s, while the hydrocarbon tolerant Cirratulid polychaets together with other tolerant deposit feeders increased in the same period.

In 1996 when the regional surveys started in the Norwegian sector, the fauna in the central part of the region was still dominated by Cirratulids and other deposit feeders. In 1999 a shift in the fauna community was observed from a fauna dominated by hydrocarbon tolerant deposit feeders to a fauna highly dominated by the former common species in the area, M. oculata. In 2002 the numbers of this species exploded in the area, in 2005 there was still found high but decreasing numbers of $M$. oculata together with several other hydrocarbon sensitive suspension feeders in the fauna. In 2005 this is reflected in an 
increasing biodiversity in Region I. Very high numbers of $M$. oculata was only found in the vicinity of the oil fields, $250 \mathrm{~m}$ and $500 \mathrm{~m}$. Although a reduction in the numbers of $M$. oculata was registered even at the $500 \mathrm{~m}$ stations from 2002. The abundance of M. oculata did not decrease from 2002 to 2005 at the $250 \mathrm{~m}$ stations.

The results from the monitoring studies reveal an ongoing general improvement in the environment in Region I from 1996 to 2005, until at least $500 \mathrm{~m}$ from the oil field centres. There are trends indicating slow improvements also at the $250 \mathrm{~m}$ stations. In general the fauna composition indicates a decreasing supply of organic matter (including degraded petroleum hydrocarbons) to the benthos and with that reduced level of hydrocarbons in the sediments. The biodiversity indices in Region I are increasing. Although high abundances of dominating species and with that reduced biodiversity in the fauna community close to the oil fields still indicate a relatively high availability of organic matter.

\section{References}

[1] McGlade, J.M. 2002. The North Sea Large Marine Ecosystem. In K. Sherman and H.R. Skjoldal, eds. Large Marine Ecosystems of the North Atlantic-Changing states and Sustainability. Forthcoming volume, Elseviers. 339-412.

[2] Kröncke, I \& Bergfeld, C. 2001. Synthesis and New Conception of North Sea Research. Working Group 10: Review of the Current Knowledge on North Sea Benthos. Zentrum für Meeres- und Klimaforschung der Universität Hamburg.

[3] Det Norske Veritas, 2006. Environmental Monitoring Region I, 2005, Main Report 2006-0187 (rev 01). Report for BP NORGE AS.

[4] Bray, J.R. \& J.T. Curtis 1957: An ordination of the upland forest communities of southern Wisconsin. Ecol. Monogr. 27: 325-349.

[5] Lance, G. N. \& W.T. Williams, 1967: A general theory of classificatory sorting strategies. II. Clustering systems. -Computer Jour. 10: 271-277.

[6] Kruskal, J.B. \& M. Wish. 1978: Multidimensional scaling. Sage Publishers. California. 93s.

[7] Phillips, D.J.H. \& Rainbow, P.S. 1994. Biomonitoring of trace Aquatic contaminants. Chapman \& Hall, London.

[8] Eisma, D., and Kalf, J. (1987). Dispersal, concentration and deposition of suspended matter in the North Sea. J. Geol. Soc. London, 144, 161-178.

[9] Hartley, J.P. 1983. Ten years of environmental monitoring at Ekofisk: A review prepared for Phillips Petroleum Company Norway. Oil Pollution Research Studies Council, Orielton Field Centre, Pembroke, Dyfed, U.K. SA71 5EZ

[10] Hiscock, K., Langmead, O., Warwick, R. \& Smith, A. 2005. Identification of seabed indicator species to support implementation of the EU Habitats and Water Framework Directives. Second edition. Report to the Joint Nature Conservation Committee and the Environment Agency from the 
Marine Biological Association. Plymouth: Marine Biological Association. JNCC Contract F90-01-705. 77 pp.

[11] Pearson, T.H. \& Rosenberg, R., 1978: Macrobenthic succession in relation to organic enrichment and pollution of the marine environment. Oceanogr. Mar. Biol. Ann. Rev., Vol. 16: 229-311.

[12] Simboura, N. and Zenetos, A. 2002. Benthic indicators to use in Ecological Quality classification of Mediterranean soft bottom marine ecosystems, including a new Biotic Index. Mediterranean Marine Science Vol. 3/2, 2002, 77-111.

[13] Gray, J.S., Clarke, K.R., Warwick, R.M., Hobbs, G. 1990: Detection of initial effects of pollution on marine benthos: An example from the Ekofisk and Eldfisk oilfields, North Sea.

[14] Det Norske Veritas, 2000. Environmental Monitoring Region I - Ekofisk, Main Report 2000-3238 (rev 01) Report for BP AMOCO/STATOIL/PHILLIPS. Det Norske Veritas, 2003.

[15] Det Norske Veritas, 2003. Environmental Monitoring Region I -Ekofisk, 2002, Main Report 2003-0338 (rev 01). Report for CONOCO PHILLIPS/BP /STATOIL 